\title{
Survival of Out-of-Hospital Cardiac Arrest by Early Defibrillation in the Sorrento Peninsula
}

\author{
Maurizio Santomauro ${ }^{1 *}$, Vincenzo laccarino ${ }^{2}$, Salvatore Criscuolo ${ }^{3}$, Adele Ferro ${ }^{4}$, Carla Riganti ${ }^{5}$, Mario \\ Alberto Santomauro ${ }^{1}$, Raffaele Giordano ${ }^{1}$, Mario Petretta ${ }^{6}$, Francesco Elia ${ }^{6}$ and Domenico Bonaduce ${ }^{6}$
}

${ }^{1}$ Department of Cardiovascular Emergency, Internal Medicine and Geriatric, School of Medicine, Federico II University, Italy

${ }^{2}$ Department of Cardiology, Sorrento Hospital, ASL NA3 Sud, Italy

${ }^{3} 118$ Operations Centre ASL NA3, Castellammare di Stabia, Italy

${ }^{4}$ Biostructures and Bioimaging Institute, Centro Nazionale di Ricerche, Italy

${ }^{5}$ Public Health, Azienda Ospedaliera Universitaria Federico II, Italy

${ }^{6}$ Department of Translational Medicine, School of Medicine, Federico II University, Italy

\begin{abstract}
Background: Out-of-hospital cardiac arrest (OHCA) is a critical public health problem also in Italy. The use of Automated External Defibrillator (AED) by non-healthcare professionals was approved in Italy since 2001. The number of installed AED was increased in Italy annually since 1999 and the number of sold AED was more than 50.000 units until 2017. Nevertheless, there were about 60.000 OHCA annually. For this reason, we investigated, using retrospective regional register study, the efficacy of Public Access Defibrillation (PAD) interventional program in terms of survival rate for patient suffering of OHCA with shockable rhythm rescued by bystanders compared to traditional 118 Emergency Medical Service (EMS) System activation.
\end{abstract}

Methods: We elaborated and activated a PAD program adapted to logistical characteristics of Sorrento Peninsula. After an adequate training period, we proceeded to analyse OHCA register data in the period of time from January 2007 to September 2017. We selected all events of OHCA with presumable cardiac aetiology triggered by ventricular fibrillation (VF) or pulseless ventricular tachycardia ( $\mathrm{pVT}$ ) and for these events we compared two different type of intervention: EMS personnel's rescue (Group A) and bystanders' rescue (Group B). Furthermore, we analysed the number of OHCA and survivors rate at discharge and at one month. Finally, we studied the negative and positive predictive factors for survivors rate in OHCA patients.

Results: 138 patients fulfilled the inclusion criteria. There were no differences of age, gender and OHCA setting between two groups. The mean time from collapse to defibrillation was $16.6 \pm 5.4$ minutes in Group A and $6.9 \pm 2.6$ minutes in Group B ( $p=0.001)$. $80.2 \%$ of OHCA occurred at home, $19.8 \%$ occurred outdoors. The increase of early survival was statistically significant, and it was of $28 \%$ in Group A and of $45 \%$ in Group B (p 0.05) (95\% Cl $1.044-1.065)$. Furthermore, the survival rate at one month decreased of $12 \%$ in Group A and of $23 \%$ in Group B (p 0.05) (95\% Cl 1.058 - 1.086).

Conclusion: This Registry demonstrated that PAD program is essential to increase the survivors, in particular in regions with densely populated area and with insufficient road network. In these areas it is essential to increase the number of AED installation and the Cardiopulmonary Resuscitation (CPR) training among the general population. Strong positive predictive factors of outcome were a short delay to defibrillation, bystander CPR and place of collapse.

\section{Introduction}

Cardiac Arrest (CA) is defined as an unexpected event leading to sudden death that occurs in subjects with undiagnosed or stable pre-existing cardiac disease in less than one hour and without precocious signs. Some recent clinical studies in Europe showed that the survival after OHCA was increased from $2.5 \%$ to $24 \%$ after PAD implementation (Table 1) [1-6]. In Italy more than 60.000 citizens die for OHCA every year and the survival rate after PAD program increased
*Corresponding author: Maurizio Santomauro, MD, FESC, FHRS, Department of Cardiovascular Emergency, Internal Medicine and Geriatric, School of Medicine, Federico II University, Via Sergio Pansini 5-80131, Naples, Italy

Accepted: January 22, 2019

Published online: January 24, 2019

Citation: Santomauro M, laccarino V, Criscuolo S, et al. (2019) Survival of Out-of-Hospital Cardiac Arrest by Early Defibrillation in the Sorrento Peninsula. Ann Heart 4(1):68-73 
Citation: Santomauro M, laccarino V, Criscuolo S, et al. (2019) Survival of Out-of-Hospital Cardiac Arrest by Early Defibrillation in the Sorrento Peninsula. Ann Heart 4(1):68-73

Table 1: The main European studies that investigate the the outcome of out-of-hospital cardiac arrest with PAD programs.

\begin{tabular}{|l|l|l|l|l|l|l|l|}
\hline Country & Time & Population & CA in public (\%) & Schockable Rhythm (\%) & Bystanders BLS (\%) & ROSC (\%) & Survival (\%) \\
\hline Netherlands(1) & $2000-2002$ & W-OHCA & 71 & 67 & 47 & 57 & 18 \\
\hline Norway(2) & $2001-2008$ & A-OHCA & 33 & 47 & 73 & 43 & 24 \\
\hline Sweden(3-4) & $2005-2006$ & A-OHCA & 35 & 19 & 39 & 27.7 & 6.8 \\
\hline Ireland(5) & $2004-2006$ & A-OHCA & 8.7 & 34.5 & 32.5 & 6.7 \\
\hline Austria(6) & $2002-2004$ & A-OHCA & 45 & 42 & ND & ND & 2.5 \\
\hline
\end{tabular}

PAD: Public access to defibrillation; CA: Cardiac arrest; BLS: Basic life support; ROSC: Return of spontaneus circulation; A-OHCA: All out-ofhospital cardiac arrest; W-OHCA: Witnessed out-of-hospital cardiac arrest.

Table 2: The main italian studies from ' 90 that investigate the outcome of out-of-hospital cardiac arrest with PAD programs.

\begin{tabular}{|c|c|c|c|c|c|c|c|}
\hline City or Region & Time & Population & $\begin{array}{l}\text { CA in } \\
\text { public (\%) }\end{array}$ & $\begin{array}{l}\text { Schockable } \\
\text { Rhythm (\%) }\end{array}$ & $\begin{array}{l}\text { Bystanders } \\
\text { BLS (\%) }\end{array}$ & $\begin{array}{l}\text { ROSC } \\
\text { (\%) }\end{array}$ & $\begin{array}{l}\text { Survival } \\
\text { (\%) }\end{array}$ \\
\hline Torino(7) & 1992-1994 & BW-OHCA & 14 & 32 & 28 & 18 & 9.7 \\
\hline Mestre(8) & 1996-1997 & BW-OHCA & ND & 73 & 40 & 33 & 13 \\
\hline Piacenza(9) & $1999-2000$ & A-OHCA & 13 & 24 & ND & 13 & 11 \\
\hline Brescia(10) & $1997-2002$ & $\mathrm{~A}-\mathrm{OHCA}$ & 14 & 30 & 21 & 10 & 4.4 \\
\hline Forli(11) & $1994-2005$ & BW-OHCA & 26 & 38 & ND & ND & 15 \\
\hline Friuli Venezia Giulia(12) & 1994 and $2003-2004$ & Non-EMS W-OHCA & 23 & 20 & 25 & 27 & 10.3 \\
\hline Lombardia(13) & 2000 and 2003 & A-OHCA & 25 & 14 & 22 & 24 & 3.4 \\
\hline Cernusco sul Naviglio(14) & $2003-2004$ & S-OHCA & ND & 14 & 22 & 24 & 3.4 \\
\hline Bologna(15) & 2004-2007 & AW-OHCA & 80 & 33 & 50 & 34 & 10 \\
\hline
\end{tabular}

CA: Cardiac arrest; BLS: Basic life support; ROSC: Return of spontaneus circulation; BW-OHCA: Bystander witnessed out-of-hospital cardiac arrest; PAD: Public access to defibrillation; A-OHCA: All out-of-hospital cardiac arrest; Non-EMS W-OHCA: Non emergency medical service witnessed out-of-hospital cardiac arrest; S-OHCA: Out-of-hospital cardiac arrest with shockable rhythms; AW-OHCA: All witnessed out-ofhospital cardiac arrest.

from $1.4 \%$ to $13 \%$ during the last ten years (Table 2) [715]. Gold standard therapy for PVT and for VF is precocious defibrillation and it is considered the only intervention able to increase the survival in case of OHCA [16-19]. However, success rate in the resuscitation is strictly related to time interval occurring between collapse to defibrillation. 10 minutes delay in using AED is associated with very low survival chances $(2 \%)$, survival probability decreases of $10 \%$ for each minute and long brain damages can occur after 4-5 minutes of anoxia. Correct activation of 4-step "survival chain" plays a fundamental role in providing prompt AED. The organization of volunteer teams trained for BLSD and endowed with AED showed to be a particularly effective instrument to increase survival [20-22].

\section{Aims}

We investigated using retrospective regional register study the efficacy of PAD interventional program in terms of survival rate at discharge and at one month in patients presenting OHCA with shockable rhythm rescued by bystanders compared to traditional 118 EMS System activation. Furthermore, we analysed the negative and positive predictors for survivors rate in OHCA patients.

\section{Material and Methods}

We provided an implementation of early defibrillation project with the organization of a PAD program in the Sorrento Peninsula. This area has a surface of $192.13 \mathrm{Km}^{2}$, longitudinally crossed by Lattari mountain range sloping towards the sea to Punta Campanella. The municipalities involved in the project were Vico Equense, Meta, Piano di Sorrento, Sant'agnello, Sorrento and Massa Lubrense, with 81.810 citizens in total.
Four different models of AED were provided from June 2012 (Powerheart G3 Plus Cardiac Science, Powerheart G5 Cardiac Science, Lifepak CR Plus Physio Control, Heart start Onsite Philips) with electrocardiographic data store. A total of 128 AED was installed in post offices, schools, pharmacies, hotels, seaside resorts, businesses, restaurants, malls, sports fields, train stations and main squares (Figure 1). For our study, 501 voluntairs were trained in the AED use and their cardiopulmonary resuscitation skills were refreshed. First responders were trained in pairs for 8 hour sessions. Refresher training was conducted at 24 months intervals. 138 patients that has OHCA in the Sorrento Peninsula area from January 2012 to September 2017 were eligible for our analyses. The trial population included patients aged $>18$ years who underwent OHCA of cardiac aetiology, excluding traumatic causes. All data were obtained from the Registry of the Emergency Medical System (EMS) 118 ASL NA3 of Sorrento Peninsula. The collected data were: Setting of OHCA, the estimated moment of the collapse, rate of the witnesses OHCA, rate of bystander CPR applied, rate of defibrillation (including defibrillation by EMS), rate of return of spontaneous circulation (ROSC) prior to arrival at the hospital, the number of delivered defibrillation shocks, sequence of events, and relevant time points at 30 day survival rate according to the Utstein style [23]. The electrocardiograms were downloaded from AED and from manual defibrillators, voice recordings were downloaded from AED. Time of call, dispatching, and first responders' and ambulances' arrival on the scene were obtained from EMS computers. The dates of death or discharge were obtained from hospital records. Then for all selected OHCA events we compared two different type of intervention: EMS personnel's rescue (Group A) 


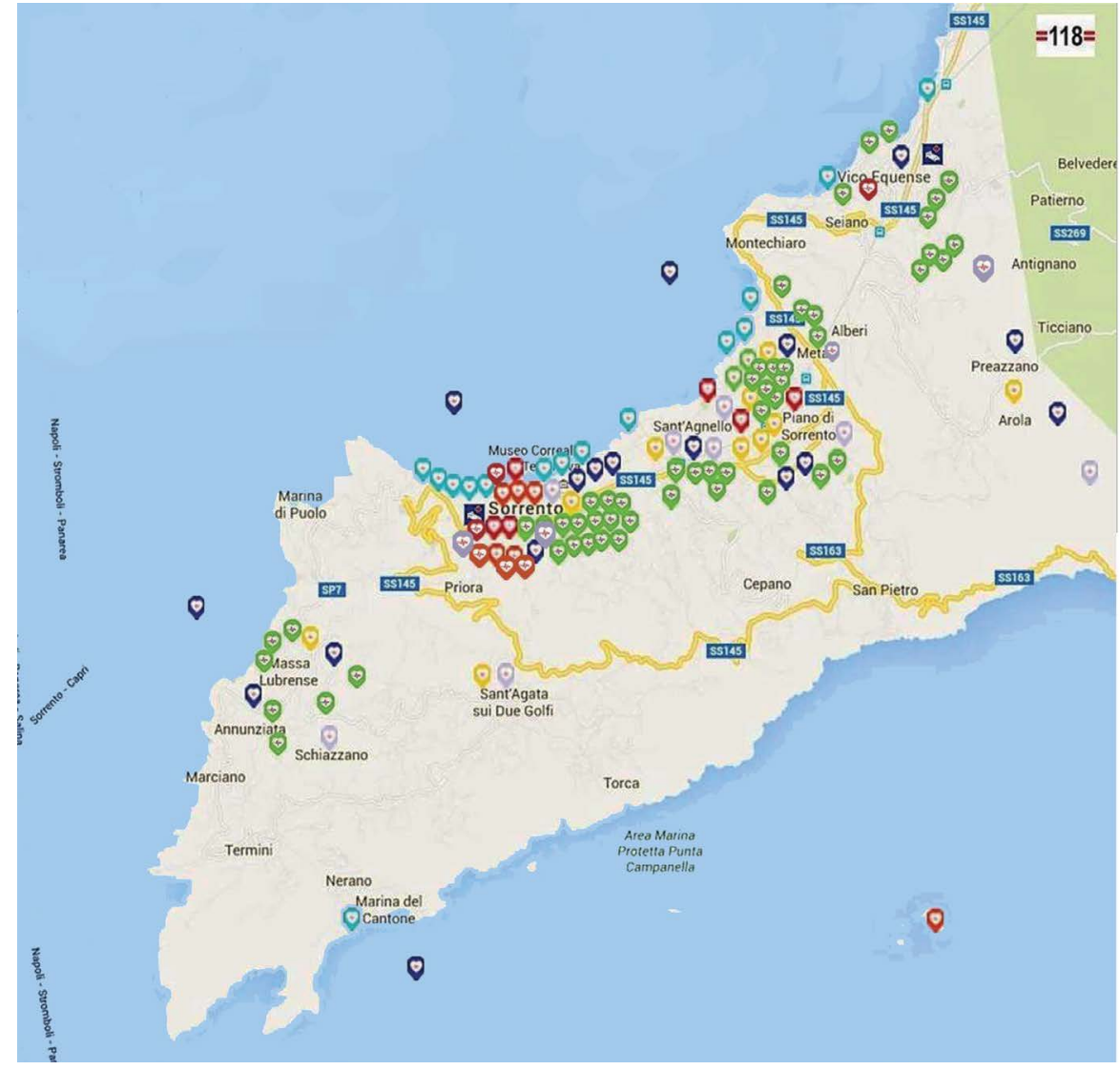

- POLICE STATIONS

OSCHOOLS AND PARISHES

O PUBLIC BUILDINGS

D BEACHES

PHARMACIES

OHOTELS, RESTAURANTS, BAR

SPORTS GROUNDS, GYMS

Figure 1: AED Distribution in Sorrento Peninsula.

Table 3: Demographic data and preexisting diseases.

\begin{tabular}{|l|l|l|l|}
\hline & $\begin{array}{l}\text { Group A } \\
(\mathbf{n = 1 1 5})\end{array}$ & $\begin{array}{l}\text { Group B } \\
(\mathbf{n = 2 3 )}\end{array}$ & $\mathbf{P}$ \\
\hline Age (years) & $64.5 \pm 12.2$ & $67.4 \pm 12.5$ & n.s. \\
\hline Sex (m/f) & $65 / 50$ & $15 / 8$ & n.s. \\
\hline Preexisting disease & & & \\
\hline Cardiocirculatory diseases (n/\%) & $8(7 \%)$ & $3(13 \%)$ & n.s. \\
\hline Others (n/\%) & $17(15 \%)$ & $5(22 \%)$ & n.s. \\
\hline Setting of OHCA & & & \\
\hline On the street (n/\%) & $53(46 \%)$ & $13(56 \%)$ & n.s. \\
\hline Home (n/\%) & $38(33 \%)$ & $6(27 \%)$ & n.s. \\
\hline Nearby the beach (n/\%) & $24(21 \%)$ & $4(17 \%)$ & n.s. \\
\hline
\end{tabular}

Data of age are mean \pm SD; n.s. : not significant.

and bystanders' rescue (Group B). Finally, we analysed as predictive factor the time from CA to defibrillation, presence of shockable rhythm, bystander as first rescuer, the setting of OHCA, timing of call to EMS, road condition, gender, age, presence or absence of concomitant diseases, number of shocks with AED.

\section{Statistical Analysis}

Chi-square test for categorical variables was used to test the relationship between sudden death occurred in case of resuscitation attempt performed by 118 emergency system (Group A) and performed by bystanders (Group B). Unpaired Student's t-test for normally distributed variables and MannWhitney U-test for non-normally distributed variables were used to test the statistical significance at a $p$-value $<0,05$. The statistically software used was SPSS Inc., Advanced Model 15.0 (Chicago Illinois).

\section{Results}

A total number of 138 reported cases fitting the inclusion criteria. Demographic data showed no difference between groups (Table 3 ). The mean time from collapse to defibrillation was $16.6 \pm 5.4$ minutes in Group $A$ and $6.9 \pm 2.6$ minutes in Group B ( $p<0.001), 80.2 \%$ of OHCA occurred at home, $19.2 \%$ outdoors. The time arrival of EMS to the emergency scene was $16.3+3.2$ minutes (Group A) and $18.4+3.4$ minutes (Group B) (n s). The time from collapse to CPR decrease from $16.4+3.2$ minutes (Group A) to $5.1+2.3$ minutes (group B) (p $<0.05)$. For a total of 138 patients, 115 patients (83.3\%) were rescued by Group A while 23 patients (16.7\%) were rescued by Group B. Sudden death occurred in 84 of 115 patients (73\%) in which the resuscitation was attempted by Group $A$ and in 11 of 23 patients (47.8\%) in which the resuscitation was attempted by Group B $(p<0.05)$ (Figure 2). The increase of early survival was statistically significant, and it was of $27 \%$ in Group A and of $52.2 \%$ in Group B (p 0.05) $(95 \% \mathrm{Cl} 1.044$ 1.065). There was also a decrease of the survival rate at one month: $12 \%$ in Group A and $23 \%$ in Group B (p 0.05) $195 \% \mathrm{Cl}$ 1.058 - 1.086). The number of shocks recorded was less than 4 in $21.2 \%$ of cases (Group A) and in $50.2 \%$ of cases (Group B) $(p<0.05)$. Analysing data from both groups we found negative predictive factors and positive predictive factors of outcome (Table 4). 


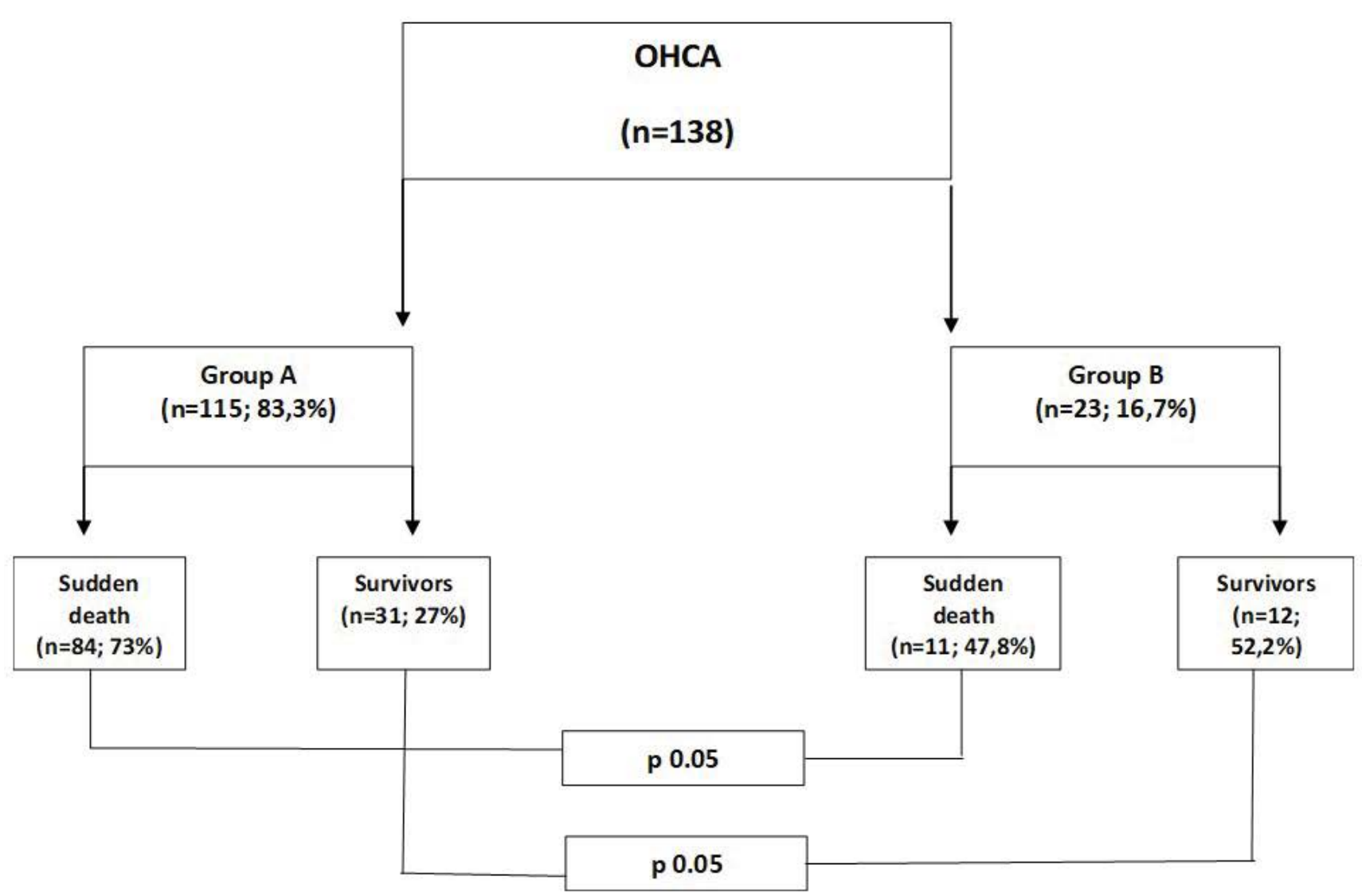

Figure 2: Results: a flow chart of Out of Hospital Cardiac Arrest in Group A and Group B.

Table 4: Predictive factors of outcome.

\begin{tabular}{|l|l|}
\hline Negative Predictive Factors & Positive Predictive Factors \\
\hline Mean time from cardiac arrest to defibrillation of 12/14 minutes & Short time (<10 minutes) from cardiac arrest to CPR and defibrillation \\
\hline Non shockable rhythm & Bystander as first rescuer \\
\hline Cardiac arrest at home & Public place (street, square) \\
\hline Delayed call of emergency medical service & Early call of emergency medical service \\
\hline Road traffic & Good road conditions \\
\hline Male sex & Female sex \\
\hline Elderly age and concomitant diseases & Young people without concomitant diseases \\
\hline$>4$ schocks with AED & $<4$ shocks with AED \\
\hline
\end{tabular}

\section{Discussion}

Our Registry assessed the performance of bystanders' CPR and AED use for improving survival from OHCA in a particular region of Italy. According to Rochester study, the Authors showed that endowing police teams with AED reduced response time interval to $6 \mathrm{~min}$ and provides a survival rate of $65.2 \%$ by bystander-witnesses VF/pVT [24]. As expected, there was a clear inverse association between the delay to defibrillation and survival [25-30]. These results highlighted the importance of reducing the delay to defibrillation even further, with the help of AED proper allocations in public access all over the region. We found a decreased delay defibrillation with the raise of AED allocations. According to American Heart Association (AHA) 2015 guidelines, it is desiderable to install AED in locations where OHCA is more frequent [31-32]. In our study, we determined also the number of delivered defibrillation shocks during the first 30 min of CPR. The number of shocks recorder are less than 4 in $21.2 \%$ of cases in Group A and in $50.2 \%$ of cases in Group B ( $p<$ 0.05 ). Choosing the best threshold value at 4 , the delivery of $<$ 4 shocks predicted survivors. Indeed there was a reduction of survival rate for $>4$ schocks [33]. According to the AHA 2015 OHCA guidelines [31], a defibrillation shock can be delivered every $2 \mathrm{~min}$ and the following four shocks can be delivered with a delay of 8-10 min. Furthermore, the EMS response time is critical. Road traffic, especially during summer time, and absence of alternative itineraries through secondary road often delays emergency vehicles arrival. Road traffic and bad roads condition were identified as negative predictive factor of outcome after OHCA (Table 4). Other negative predictors of outcome were lack of resources and barriers [34]. The increase in EMS response time that was observed is worrying, according by Wissenberg, et al. experience [35]. The fact that having VF or pVT at home gives a smaller chance of initial resuscitation success when simultaneously considering 
age, gender and delay, is surprising. However other factors, such as comorbidity, probably influenced the results. In Danish Cardiac Arrest Registry [35] adult survivors of OHCA that received bystander's cardiopulmonary resuscitation (CPR) included defibrillation showed significantly decrease of all-cause mortality at 1 year compared to survivors that didn't received Bystanders's CPR .The rate of bystanders' CPR performed on these patients were from $66.7 \%$ to $80.6 \%$ $(P<0.001)$ during the study period; the rate of bystanders' defibrillation were raised from $2.1 \%$ to $16.8 \%(P<0.001)$. The Danish Author explained that during the study many initiatives began in Denmark for obtaining these improvements, like mandatory CPR courses as in elementary schools, as for obtaining driving license. Recently, also in Italy with the law of the "Good School" [36] the education of the CPR and the use of the AED started. However, even in Italy, it is important that each cardiac arrest intervention project had a database of the interventions. The registries can be used to determine how often bystanders perform CPR and defibrillate patients. We observed that in Sorrento Peninsula there was a marked increase of bystanders' CPR and bystanders' defibrillation after the organization of PAD program. Collecting high-quality data is essential and forms the basis for healthcare decisions and for resources allocation [37].

\section{Conclusion}

This Registry demonstrated that the PAD program is essential for increase survival after OHCA, in particular in region with densely populated areas and with insufficient road network. In this areas it is necessary to raise the number of AED installation. Furthermore, it is desirable to install AED in location where OHCA is more frequent according to American Heart Association (AHA) 2015 guidelines. It is also important to spread BLS education further in the ordinary citizens. Finally, this Registry showed that positive predictive factors of outcome are a short delay to defibrillation, bystanders' CPR and the place of collapse.

\section{Conflict of Interest}

No conflict of interest was declared by the authors.

\section{Financial Disclosure}

The authors declared that this study has not received financial support.

\section{Acknowledgement}

We are grateful to the staff of Emergency Medical Sistem of 118 ASL NA3, Sorrento Peninsula, for their excellent organization and training.

\section{References}

1. Van Alem AP, Vrenken RH, De Vos R, et al. (2003) Use of automated external defibrillator by first responders in out-ofhospital cardiac arrest: prospective controlled trial. BMJ 14: 328396.

2. Lindner TW, Soreide E, Nilsen OB, et al. (2011) Good aoutcome in every fourth resuscitation attempt is achievable: An Utstein template report from the Stavanger region. Resuscitation 82: 1508-1513.
3. Hollenberg J, Riva G, Bohm K, et al. (2009) Dual dispatch early defibrillation in out-of-hospital cardiac arrest: The SALSA-pilot. Eur Heart J 30: 1781-1789.

4. S Lundin, J Silfverstolpe, L Svensson, et al. (2011) Increase in survival and bystander CPR in out-of-hospital shockable arrhythmia: Bystander CPR and female gender are predictors of improved outcome. Experiences from Sweden in an 18-year perspective. Heart 97: 1391-1396.

5. Moore MJ, Hamilton AJ, Cairns KJ, et al. (2008) The Northern Ireland Public Access Defibrillation (NIPAD) study: Effectiveness in urban and rural populations. Heart 94: 1614-1619.

6. Fleischhackl R, Roessler B, Domanovits $H$, et al. (2008) Results from Austria's nationwide public access defibrillation (ANPAD) programme collected over 2 years. Resuscitation 77: 195-200.

7. Casaccia M, Bertello F, Sicuro M, et al. (1995) Out-of-hospital cardiac arrest in an experimental model of the management of cardiologic emergencies in a metropolitan area. G Ital Cardiol 25: 127-137.

8. D'Este F, Busetto L, Russo G, et al. (1998) Extrahospital cardiac arrest: the experience of Mestre Emergency Service. G Ital Cardiol 28: 678-686.

9. Capucci A, Aschieri D, Piepoli MF, et al. (2002) Tripling survival from sudden cardiac arrest via early defibrillation without traditional education in cardiopulmonary resuscitation. Circulation 106: 1065-1070.

10. Cappato R, Curnis A, Marzollo P, et al. (2006) Prospective assessment of integrating the existing emergency medical system with automated external defibrillators fully operated by volunteers and lay persons for out-of-hospital cardiac arrest: the Brescia Early Defibrillation Study (BEDS). Eur Heart J 27: 553-561.

11. Fabbri A, Marchesini G, Spada M, et al. (2006) Monitoring intervention programmes for out-of-hospital cardiac arrest in a mixed urban and rural setting. Resuscitation 71: 180-187.

12. Kette F, Pellis T (2007) Pordenone Cardiac Arrest Cooperative Study Group (PACS). Increased survival despite a reduction in out-of-hospital ventricular fibrillation in north-east Italy. Resuscitation 72: 52-58.

13. Citerio G, Buquicchio I, Rossi GP, et al. (2006) Prospective performance evaluation of emergency medical services for cardiac arrest in Lombardia: Is something moving forward? Eur J Emerg Med 13: 192-196.

14. Terranova P, Valli P, Severgnini B, et al. (2006) Early outcomes of out-ofhospital cardiac arrest after defibrillation: A 24 months retrospective analysis. Indian Pacing Elecrophysiol J 6: 194-201.

15. Taglieri N, Saia F, Lanzillotti V, et al. (2011) Impact of a territorial ST-segment elevation myocardial infarction network on prognosis of patients with out-ofhospital cardiac arrest. Acute Card Care 13: 143-147.

16. International Liaison Committee on Resuscitation (2005) 2005 International Consensus on cardiopulmonary resuscitation and emergency cardiovascular care science with treatment recommendations. Part 3: defibrillation. Resuscitation 67: 203-211.

17. Fridman M, Barnes V, Whyman A, et al. (2007) A model of survival following pre-hospital cardiac arrest based on the Victorian Ambulance Cardiac Arrest Register. Resuscitation 75: 311-322.

18. Holmgren C, Bergfeldt L, Edvardsson N, et al. (2010) Analysis of initial, witnessed status and delay to treatment among survivors of out-of-hospital cardiac arrest in Sweden. Heart 96: 1826-1830. 
19. Hallstrom AP, Ornato JP, Weisfeldt M, et al. (2004) Public Access Defibrillation Trial Investigators. Public-access defibrillation and survival after out-of-hospital cardiac arrest. N Engl J Med 351: 637-646.

20. Rea TD, Eisenberg MS, Becker $\sqcup$, et al. (2003) Temporal trends in sudden cardiac arrest: A 25-year emergency medical services perspective. Circulation 107: 2780-2785.

21. Folke F, Gislason GH, Lippert FK, et al. (2010) Differences between out-of-hospital cardiac arrest in residential and public locations and implications for public-access defibrillation. Circulation 122 623-630.

22. Shah AS, Bhopal R, Gadd S, et al. (2010) Out-of-hospital cardiac arrest in South Asian and white populations in London: database evaluation of characteristics and outcome. Heart 96: 27-29.

23. Jacobs I, Nadkarni V, Bahr J, et al. (2004) Cardiac arrest and cardiopulmonary resuscitation outcome reports: update and simplification of the Utstein templates for resuscitation registries. Resuscitation 63: 233-249.

24. Okubo M, Atkinson EJ, Hess EP (2017) White RD Improving trend in ventricular fibrillation/pulseless ventricular tachycardia outof-hospital cardiac arrest in Rochester, Minnesota: A 26-year observational study from 1991 to 2016. Resuscitation 120: 31-37.

25. Davis EA, Mosesso VN (1998) Performance of police first responders in utilizing automated external defibrillation on victims of sudden cardiac arrest. Prehosp Emerg Care 2: 101-107.

26. White RD, Asplin BR, Bugliosi TF, et al. (1996) High discharge survival rate after out-of-hospital ventricular defibrillation with rapid defibrillation by police, and paramedics. Ann Emerg Med 28: 480-483.

27. Herlitz J, Engdahl J, Svensson L, et al. (2006) Major differences in 1-month survival between hospitals in Sweden among initial survivors of out-of-hospital cardiac arrest. Resuscitation 70: 404409.

28. Santomauro M, Giordano R, Poli V, et al. (2012) II progetto di defibrillazione precoce della Penisola Sorrentina. G Ital Cardio 13: S46-S49.
29. Pollack R A, Brown S P, Rea T, at al. (2018) Impact of Bystander Automated External Defibrillator Use on Survival and Functional Outcomes in Shockable Observed Public Cardiac Arrests. Circulation 137: 2104-2113.

30. Baekgaard JS, Viereck S, Palsgaard Moller T, et al. (2017) The Effects of Public Access Defibrillation on Survival After Out-ofHospital Cardiac Arrest. A systematic Review of Observational Studies. Circulation 136: 954-965.

31. Travers AH, Perkins GD, Berg RA, et al. (2015) 2015 International Consensus on Cardiopulmonary Resuscitation and Emergency Cardiovascular Care Science With Treatment Recommendations - Part 3: Adult Basic Life Support and Automated External Defibrillation. Circulation 132: S51-S83.

32. Tsukigase K, Tanaka H, Takyu H (2017) Mismatch between Sites of Incidence of Out-of-Hospital Cardiac Arrest and Locations of Installed Automated External Defibrillator in the Tokyo Metropolitan Area W J of Card Dis 7: 185-194.

33. Jouffroy R, Ravasse $P$, Saade A, et al. (2017) Number of Prehospital Defibrillation Shocks and the Return of Spontaneous Circulation in Out-of-Hospital Cardiac Arrest Turk J Anaesthesiol Reanim 45: 340-345.

34. Smith CM, Lim Choi Keung SN, Khan MO, et al. (2017) Perkins G D Barrier and facilitators to public access defibrillation in out-ofhospital cardiac arrest: A systematic review Eur Heart JournalQuality of Care and Clinical Outcome 3: 264-273.

35. Wissenberg M, Folke F, Hansen C M, et al. (2015) Survival After Out-of-Hospital Cardiac Arrest in relation to Age and Early Identification of Patients with Minimal Change of Long-Term Survival. Circulation 131: 1536-1545.

36. (2015) Legge n.107 "La Buona Scuola". Gazzetta Ufficiale Repubblica Italiana, Serie Generale n 162: 15-17.

37. Rajagopal S, Booth SJ, Brown TP, et al. (2017) Data quality and 30-day survival for out-of hospital cardiac arrest in the UK outof-hospital cardiac arrest registry: A data linkage study Brit Medical Journal Open 7: 1-9.

DOI: $10.36959 / 652 / 395$

Copyright: ( 2019 Santomauro M, et al. This is an open-access article distributed under the terms of the Creative Commons Attribution License, which permits unrestricted use, distribution, and reproduction in any medium, provided the original author and source are credited. 